\title{
Red-Eye: A Helicopter-Based Architecture for Tactical Wildfire Monitoring Strategies
}

\author{
Enric Pastor, Cristina Barrado, Pablo Royo, Juan Lopez, Eduard Santamaria, Xavier Prats, and Josep M Batlle \\ Technical University of Catalonia \\ Av. Canal Olímpic, 15 \\ Castelldefels, Spain 08860 \\ $+34-93-413-7103$ \\ enric@ac.upc.edu
}

Abstract-This work introduces a flexible and reusable architecture designed to facilitate the development of remote sensing applications. Based on it, we are developing a helicopter system, called Red-Eye, devoted to the detection, control and analysis of wild land forest fires in the Mediterranean area. The design of the proposed system is composed of five main components. Each component will work collaboratively to constitute a platform of high added value. The general architecture designed for wildfire monitoring is being tailored for two relevant objectives within the particular Mediterranean scenario: tactical day/night fire front evolution, and post-fire hot-spot detection. ${ }^{12}$

The generalized integration of monitoring vehicles with the operation of other aerial resources (attack helicopter and airplanes) is an unsolved problem, both technically and methodologically. However, the operation of a monitoring helicopter during certain very well identified phases of the extinction process in highly plausible. High-level strategic monitoring is possible because no-conflicts will appear due to different flight levels; however, low-level tactical monitoring is a source of potentially dangerous in-flight traffic conflicts.

In addition to monitoring the fire front evolution, detection of remaining post-fire hot-spots located at the perimeter of fire is the main application that has been foreseen. Just after a fire front is contained or even during the days following the fire extinction, the monitoring tasks have to be maintained because of the danger of fire reactivation. The cost of monitoring with ground teams or aerial means it is very expensive and consumes resources needed in other fronts or possibly concurrent fires. However, a helicopter equipped with thermal cameras, can flight over the area and generate a map of hot spots with higher precision at a smaller cost. It is crucial in this application that the hot spots are reported immediately to avoid having ground brigades waiting for data for too long. Also, it is important to feedback the information in such a way it can be effectively consumed, not forcing ground brigades to walk around the forest without a clear operational scheme.

Based on a Service Oriented Architecture (SOA) [9] a heli- borne hot-spot detection system is being developed. This paper describes the global architecture of the system, including the air segment, the ground control segment, and the interface with the squads operating on the fire area, etc. We also demonstrate how the available pre-defined modules in the SOA architecture have been reused to design this particular application, the additional subsystems required to implement specific hot-spot mission requirements, and the overall system / end-user interface.

\section{TABLE OF CONTENTS}

1. INTRODUCTION ............................................................... 1

2. Problem analysis and Tactical ObJectives .......... 4

3. ARCHITECTURE OF THE RED-EYE SYSTEM ................... 5

4. SYSTEMS ON-BOARD THE HELICOPTER ........................... 6

5. AIR AND/OR GROUND COMMAND SYSTEM ........................ 7

6. GROUND-BASED SYSTEMS ..............................................9 9

7. CONCLUSIONS .......................................................... 10

ACKNOWLEDGEMENTS...................................................... 10

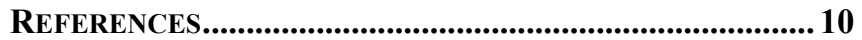

BIOGRAPHY ................................................................ 10

\section{INTRODUCTION}

Forest fires are an important problem for many countries. The economical loss is the most visible impact in the short term. The ecological damage and the impact on the wild life diversity and climate change are the most important lost in the long term. In some dramatic cases, we should add the loss of human lives directly caused by forest fire. Between 200.000--600.000 hectares (ha) are burnt every year in Europe; $80 \%$ corresponds to Mediterranean forests with high environmental value.

Figure 1(a) shows the total burned surface and the number of registered fires for the period 1995--2004 in France, Greece, Italy, Portugal and Spain. Typical yearly expenditure in forest fire fighting in Mediterranean Europe amounts to over $800 \mathrm{M} €$. Figure 1(b) depicts the distribution of expenditures per country and per fire fighting tasks. Calculation of economical losses leads to enormous values.

${ }^{1}$ 978-1-4244-2622-5/09/\$25.00 @2009 IEEE.

${ }^{2}$ IEEEAC paper \#1324, Version 2, Updated January 16, 2009 
Burned area

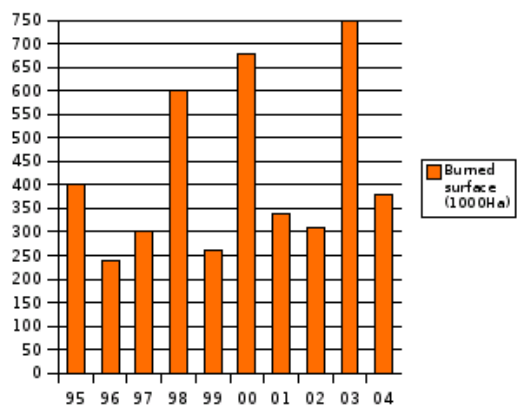

Number of fires

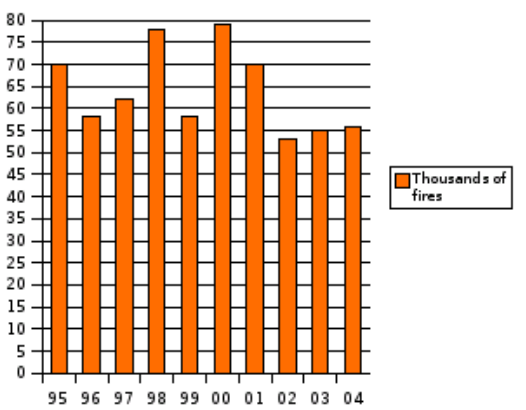

Cost distribution per country

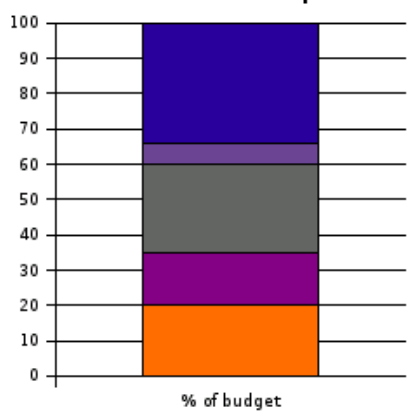

urope

Cost distribution per task

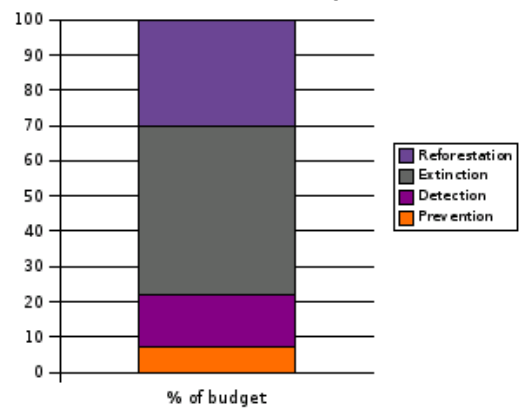

(b) Cost of fires in South Europe

\section{Figure 1. Number of wild land fires in the south Europe area and the estimated cost distribution per country and per task.}

The impact of large wildfires is felt all over the world. For example, in USA, Canada and Russia, over 1.000.000 ha, 5.000.000 ha and 1.200.000 ha are burnt per year.

This impact is accentuated in densely populated areas like Southern California in the US. The 2003 October wildfires, fueled by Santa Ana winds, were the single worst disaster in California's history, exceeding devastation of all previous fires, earthquakes and other natural disasters. At the culmination of the siege, 14 fires in 6 counties consumed over 750,000 acres of wildlands, destroying 3,338 residential structures, 33 commercial properties, 1,072 outbuildings, and claiming the lives of 26 people. The conflagration caused the greatest mobilization of fire fighting resources in California's history. All told, federal and local price tabs totaled 3 to 5 billion. Again, in October 2007 wildfires spread across Southern California. At least 1,500 homes were destroyed and over 500,000 acres of land burned from Santa Barbara County to the U.S.-Mexico border. Nine people died as a direct result of the fire; 85 others were injured, including at least 61 fire fighters.

Prevention tasks are the first way to fight against forest fire. The economical cost of the prevention tasks are directly justified by the cost of fire, but also as an investment for the long term. Inside the prevention tasks concept we may include the prescriptive fires, the firebreaks, the cleaning of dry bush, but also scientific works like the creation of vegetation maps, location of fire prone areas and the surveillance of them.
Although all important prevention efforts done at many levels, forest fire cannot be completely avoided in some extreme climatic circumstances. Fire extinguishing tasks are the second resource for fire fighting. Basically two strategies are used: Fire mitigation and fire control. Watering is mainly used for fire mitigation while dropping of other fire retardants and backfires are used to reduce the plume advance and thus for fire control.

Both fire early detection and fire monitoring during its development are crucial tasks to reduce the negative impact of wildfires. Fire monitoring not only allows managers to properly direct ground and air resources, but may also save human lives and property by getting early warning on unexpected fire behavior.

Up to now, satellites have been the primary source for strategic large area thermal imaging. Satellites like the NASA's Terra and Aqua acquire information from its Advanced Spaceborne Thermal Emission and Reflection Radiometer (the MODIS system), offer almost real-time active fire maps twice a day with automatic detection of thermal anomalies $[3,4,5]$.

Tactical monitoring has been until recently reduced to observation from the ground or from some dedicated aerial resource like command and control helicopters. However, 


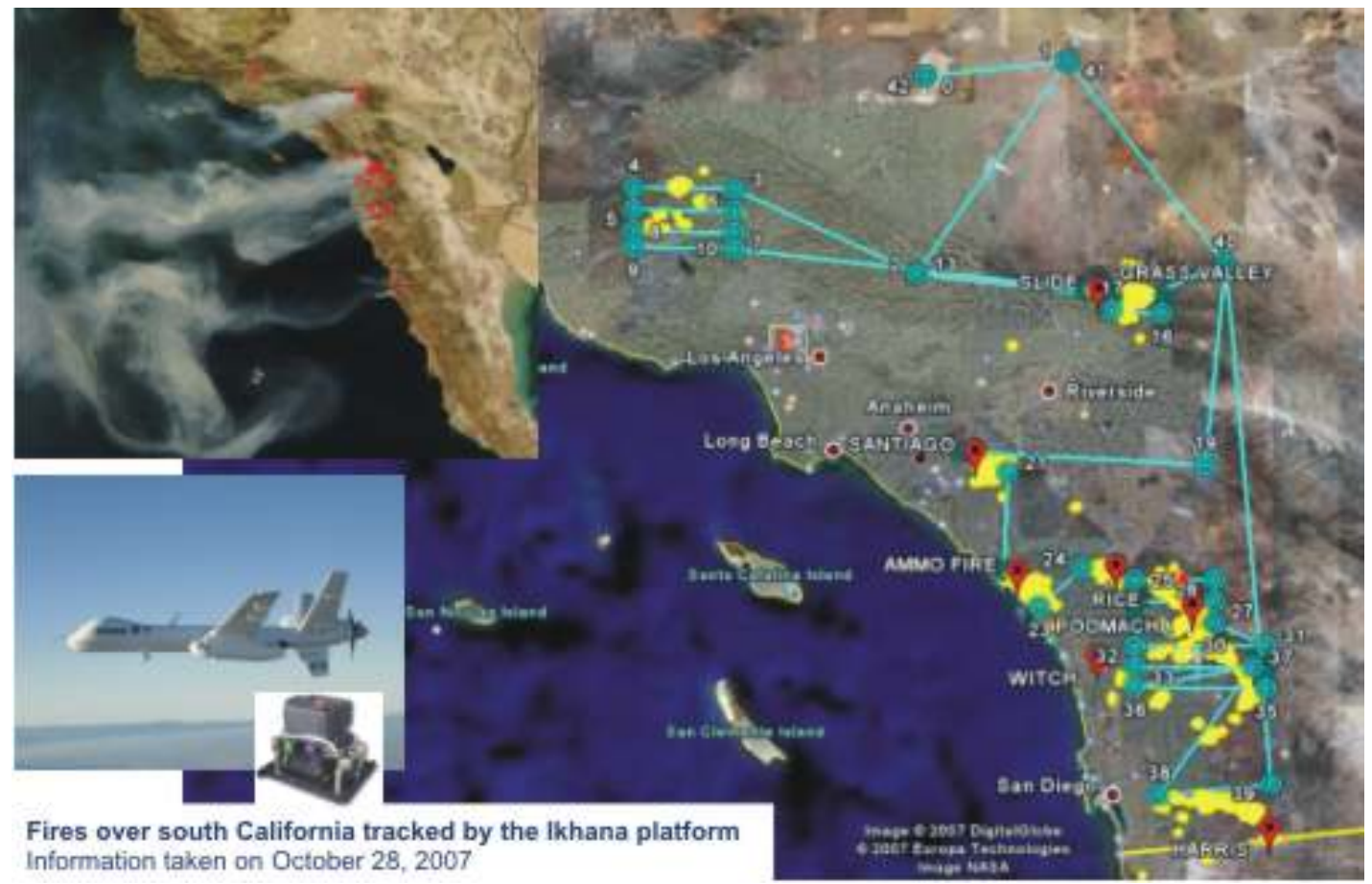

Figure 2. UAV used as strategical fire monitoring platform by NASA.

none or little technological support has been available to those in charge of these monitoring tasks.

Recently, new types of aerial vehicles; i.e. Unmanned Aerial Vehicles (UAV), have been employed as wildfire monitoring assets $[1,2,6]$. For the first time during the October 2007 California fires a UAV participated in realtime wildfire monitoring activities. NASA's Ikhana UAV flew over the major Southern California wildfires. NASA's Ikhana unmanned aircraft system flew a number of missions over several of the major Southern California wildfires from Oct. 24 until Oct. 28, capturing thermal-infrared imagery to aid fire fighters (see Figure 2 for an overview of one of the UAV missions). Ikhana, a General Atomics' Predator B adapted for civil science and technology research missions, flied long-endurance sorties lasting nine to 10 hours each from its base at NASA's Dryden Flight Research Center.

Current developments on increasingly smaller sensors, both for large aircrafts and satellites, are directly useful for smaller platforms. Most sensors are imaging technologies that include conventional cameras, infra-red/thermal cameras, multi spectrum cameras, radiometers, Doppler radar and synthetic aperture radar. Small and light costeffective conventional and infra-red cameras exist today in the COTS (commercial off-the-shelf) market than can be included right away in a UAV or a traditional helicopter. The rest of the sensor technologies are still too expensive or too heavy to be onboard these platforms, but increasing expected demands will accelerate their miniaturization. Also, new image processing techniques have been developed and now they can be embedded in small and cheap hardware boards and obtain end-users information in almost real time.

Nevertheless, a third forest fire fighting task is also needed for fire embers surveillance, once the fire is extinguished. At this time an important amount of terrestrial resources are still devoted to post fire tasks, especially if the weather conditions may provoke the resume of the fire. Ground crews have to stay on site watering the smoking spots in a typical post fire, and most times this is done blindly.

The proposed Red-Eye system is designed to improve the overall awareness of the fire managers by providing tactical support to wildfire monitoring and control of ground squads $[7,8]$. Red-Eye is built around existing COTS technology that can be immediately deployed on the field onboard traditional helicopters at a reasonable cost. Red-Eye is designed to operate from a human on-board the helicopter, and its operation can be integrated in the standard operation of aerial resources. Information is gathered by the on-board sensors, processes and then displayed in such a way it can be immediately exploited by the operator in the helicopter or relayed to the ground controller and operative squads.

A UAV-based version of Red-Eye is currently being developed. However, UAVs have several limitations both at the tactical and the strategic level that prevent their generalized operation. Essentially, the common integration of classical aerial resources and UAVs at similar flight levels is not viable without a proper separation scheme. This is not yet viable with the existing sense-and-avoid technology. 


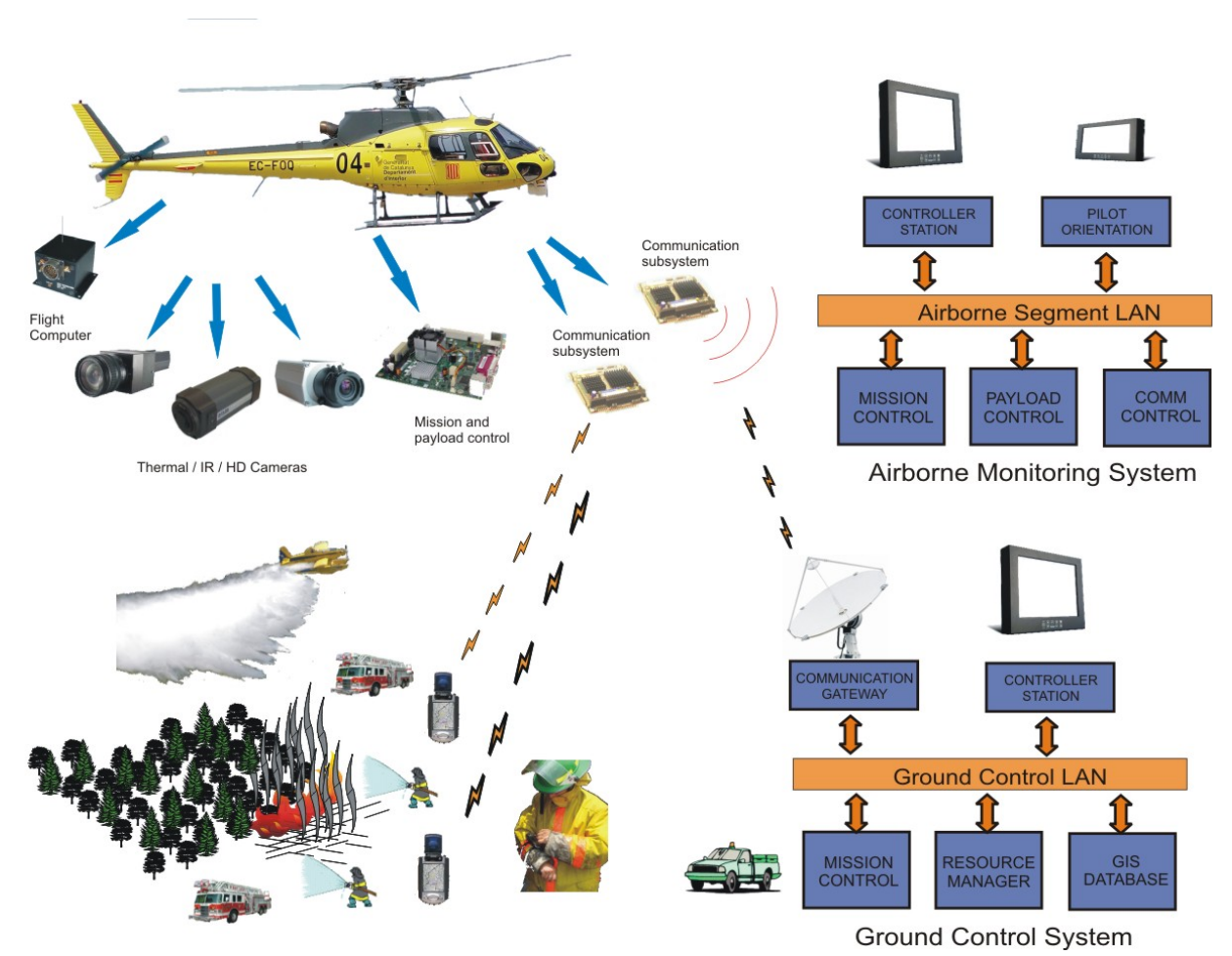

Figure 3. Architecture of the Red-Eye system: air and ground segments.

\section{Problem analysis and TaCtical OBJECTIVES}

Decisions on the forest fire management should be basically taken on the actual fire itself. However, several factors restrict the capacity to obtain a global and precise situation by those responsible of taking the right decisions (see Figure 2 for an illustrative image). Smoke on the area of the fire interferes with the ability to acquire coherent data about the actual situation. If it is necessary to obtain a global perfective of the fire, the coordinator should over-fly the area, thus leaving its control center temporally. Manned airplanes for forest-fire control cannot be used during the night or in presence of dense smoke, flying time is quite limited, available sensors on board traditional airplanes are almost non-existent, etc. Dangerous situations for the fire extinguishing personnel working on the ground may develop very rapidly.

Current technology used to collect information on the operational situation on the ground prevents that the fire fighter coordinator to choose the right decisions on time. An UAV platform capable of over flying the area of a forest fire for long periods of time and with capacity of operating from non-prepared terrains would be an extremely valuable information gathering asset, overcoming some of the aforementioned limitations. However, UAVs have extremely high operational limitations due to the lack of legislation that defines its operational requirements and imitations.
Meanwhile, a traditional aerial vehicle dedicated to fire monitoring can still offer some advantages:

(1) Payload can acquire coherent data even with bad weather or environmental conditions, like smoke.

(2) Can increase fire manager access to ubiquitous information and help to take decisions.

(3) It can also prevent dangerous situations for on-ground operators that can evolve very quickly.

(4) It can provide on-the-fly communication links between fire managers and the ground teams, especially in mountain or non-covered areas.

The above challenges are not critical to manage from a helicopter with the required technology on board. The project Red Eye proposes to develop a helicopter-based platform that will fly over the area of surveillance as long as needed and with the capacity to operate and to adapt to multiple demanding data collection scenarios thanks to its embedded computer systems.

As an example of the advantages of the use of the Red Eye system in large area surveillance we present two especially important objectives within the specific scenarios identified together with the collaboration of GRAF (Grup de Reforç d'Activitats Forestals), the selected branch from the Catalonia (Spain) Firefighters in charge of developing new operational strategies for wildland fire: 


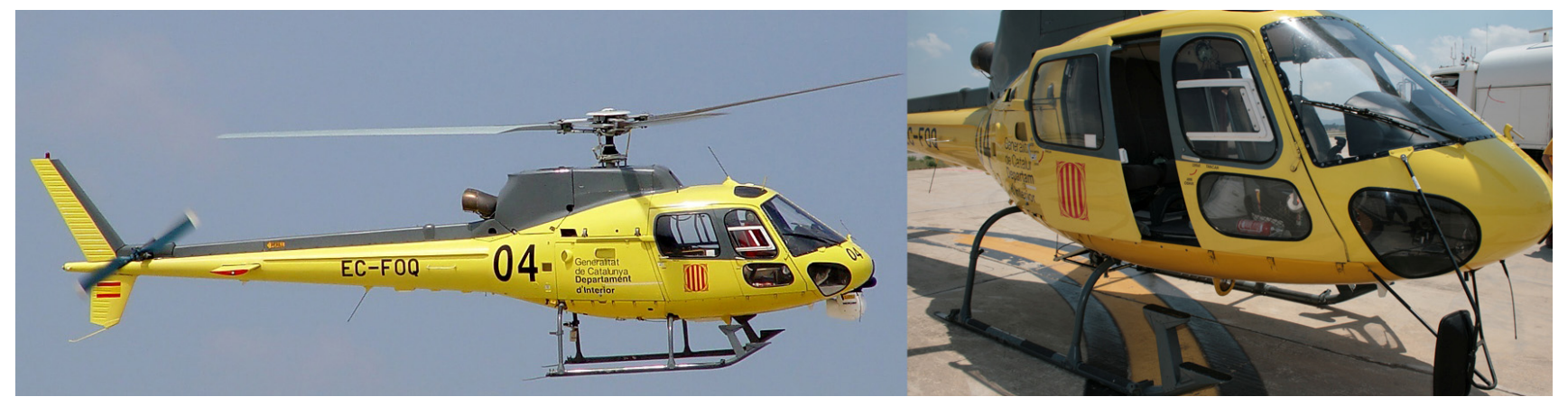

Figure 4. Eurocopter AS350 operated by the Departament d'Interior, Generalitat de Catalunya for Fire Monitoring and SAR operations.

(1) Surveillance flights during day (night flights are not possible in Spain) to gather the information required by fire-fighters to conduct extinction operations in a timely and effective way.

(2) Early morning or late afternoon flights to monitor the evolution of post-fire hot-spots during the following days of the extinction.

\section{ARCHITECTURE OF THE RED-EYE SYSTEM}

The design of the proposed Red Eye system is composed of five main components (see Figure 3). Each component will work collaboratively to constitute a platform of high added value:

(1) Manned helicopter equipped with a sensor platform and embedded control system.

(2) Airborne command and control station.

(3) Mobile ground command and control station.

(4) Ground squad information terminals.

(5) Air/ground communication infrastructure.

A helicopter and its on-board sensor and computer system. The fundamental elements of the system are the set of sensors (visible cameras, infrared and multi-spectral sensors). Their information will be collected and partially processed by the on-board computer system. Selected information will be partially transferred to ground for analysis. The overall system will be managed by an onboard operator.

Airborne command and control station. On-board the helicopter and connected to the sensors, a command station will be operated by an operator in charge of the datagathering process in order to analyze data and take the appropriate decisions. The controller will be able to decide which hot-spot points are more relevant and assign ground squads to deal with them.
A mobile ground command and control station. The fire manager working on the ground in order to direct the overall operations can get real-time information from the aerial segment. The system also allows transferring some of the decisions to the ground command, like determining if certain hot-spots are relevant or which ground teams should be directed to supervise a certain hot-spot.

Table 1: General characteristics of the Eurocopter AS350-B2 helicopter.

\begin{tabular}{|l|rl|}
\hline General Data & AS350 & B3 \\
\hline Empty Weight of Standard Aircraft & 2,716 & lbs. \\
\hline Max Takeoff Weight & 4,960 & lbs \\
\hline Useful Load & 2,244 & lbs. \\
\hline Max Takeoff Weight w. External Load & 6172 & lbs. \\
\hline Usable Fuel Capacity Standard Tank & $143 \quad$ gal. \\
\hline Baggage Compartment Volume & $35.3 \quad$ cu.ft. \\
\hline Power Plant & Turbomeca Arriel \\
& & $2 \mathrm{~B} 1$ \\
\hline Cabin Volume & $105.94 \quad$ cu.ft. \\
\hline
\end{tabular}

\begin{tabular}{|l|rl|}
\hline Performance Data & & \\
\hline Never Exceed Speed & 155 & kts. \\
\hline Fast Cruise Speed & 140 & kts. \\
\hline Maximum Range with no reserves & 359 & $\mathrm{~nm}$. \\
\hline Maximum Endurance with no reserves & 4.2 & $\mathrm{hrs}$. \\
\hline Hover In Ground Effect Ceiling & 13,285 & $\mathrm{ft}$. \\
\hline Hover Out of Ground Effect Ceiling & 11,200 & $\mathrm{ft}$. \\
\hline Takeoff Power Per Engine & 847 & shp. \\
\hline Rate of Climb & 1,979 & $\mathrm{fpm}$. \\
\hline
\end{tabular}

A set of PDA systems carried by fire squads will be integrated into a wireless network formed by the communication on-board the helicopter, the PDA themselves and the Ground Command. These PDAs will receive and present information from the Ground Command which will include data from a set of attached sensors: GPS position of the squad, wind speed and direction, ambient temperature and humidity. 

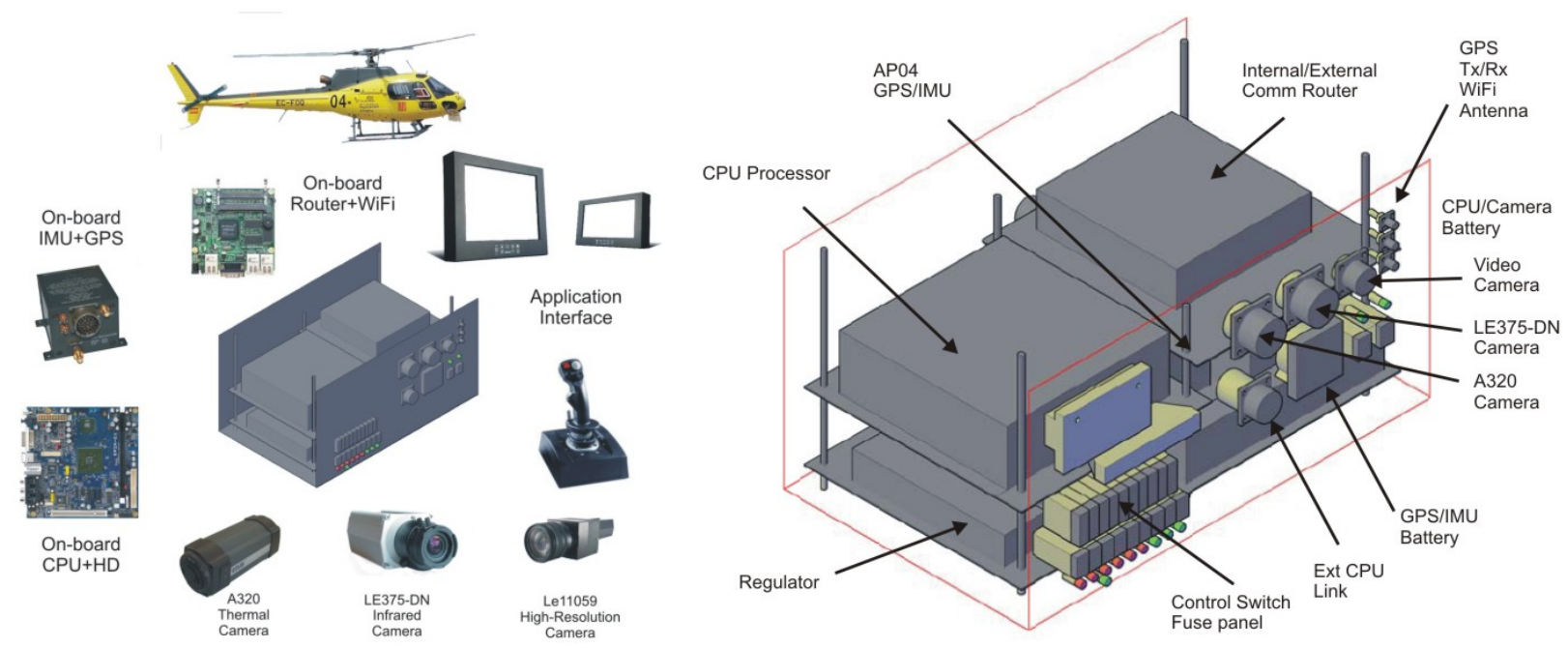

Figure 5. Airborne segment in the Red Eye system: components and 3D schematic view of the prototype integration.

Finally, the communication infrastructure. It is mixture of communication connections that must guarantee the continuous contact of the helicopter with the ground command and control station. In addition, a secondary communication infrastructure transforms the Red Eye helicopter into a communication router between grounds squads and the ground command and control.

A prototype of the Red Eye system is being built around a helicopter operated by the Catalonia government. The selected helicopter is the Eurocopter AS350 (technical details can be found in Table 1). Two units of this helicopter model (a B2 and a B3) are being operated for fire monitoring and search and rescue operations), and have been mostly selected by their availability. Figure 4 depicts a couple of images of the AS350-B2.

\section{SYSTEMS ON-BOARD THE HELICOPTER}

The air segment of the Red Eye system is composed of a set of cameras, computing and communications devices (see Figure 5). Sensing is implemented by a set of fixed mounted cameras that are calibrated to explore down to the flight direction of the helicopter. Three cameras are simultaneously operated, each one gathering data with a different objective:

\section{FLIR A320}

- Thermal Imaging.

- $\quad$ Resolution: 16 bit 320x240 pixels.

- $\quad$ Frame rate: $9 \mathrm{~Hz}$

- Connection: Ethernet 100Mbps.
- $\quad$ High resolution image.

- $\quad$ Resolution: 4000 X 2656 pixels.

- $\quad$ Frame rate: 3 fps at 4000x2656; 8.5 fps at 4000x640.

- $\quad$ Light sensitivity: 0.1 lux

- Connection: Ethernet 100Mbps

\section{Lumenera LE350C_DN}

- Medium resolution standard image/near infrared.

- $\quad$ Resolution: 2048x1536 pixels.

- $\quad$ Frame rate: 10 fps at $2048 \times 1536 ; 40$ fps at $1024 \times 768$.

- Connection: Ethernet 100Mbps.

Images will be acquired by an on-board computer system that will store the images on a system hard disk. Visible images are stored for reference, while the thermal image is processed to identify potential hot-spots. Initial filters separate those images that do not contain significant thermal information from those that contain potential hot-spots. If a thermal signature is detected then hot-spots are identified inside the image and correlated to other images taken immediately after the potential hot-spot image. Potential hot-spot images are stored and offered to the on-board operator.

The equipment on the helicopter also contains an IMU plus GPS that provides precise navigation and real-time orientation of the platform. This information will be stored correlated to the image acquisition process. Images will be only analyzed and geo-allocated if significant thermal 

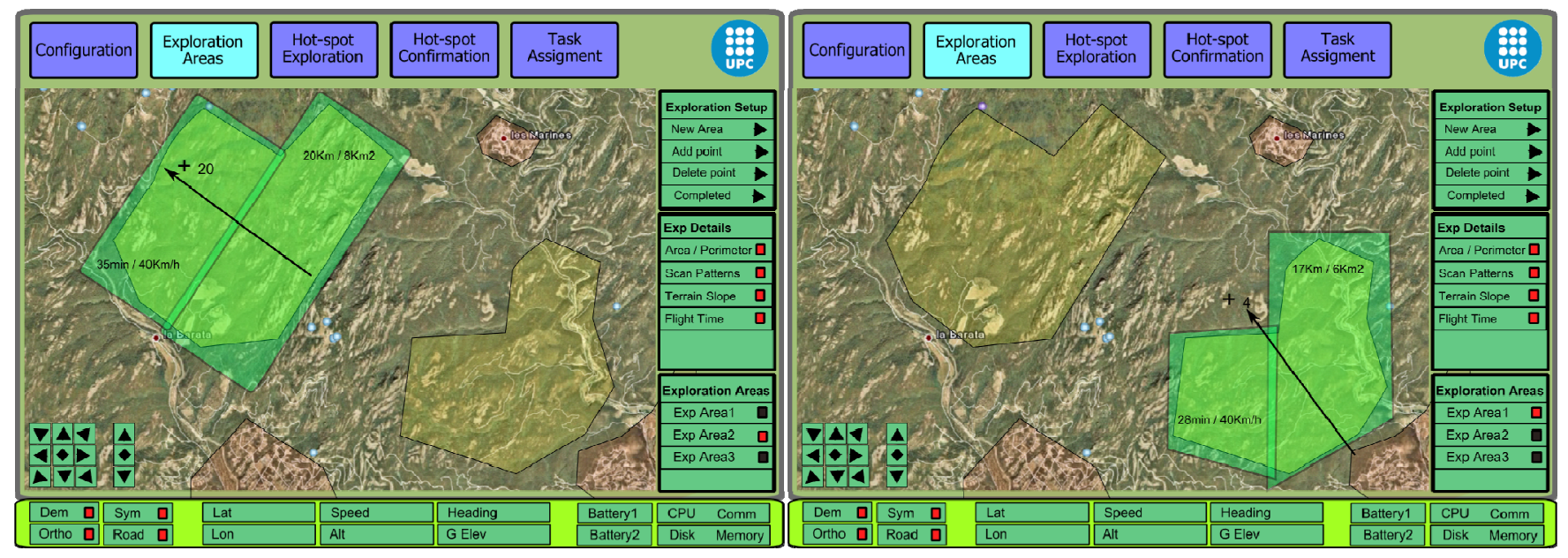

Figure 6. Exploration areas scan segments and preferred direction of the helicopter due to the elevation of the terrain.

signatures are detected. The image processing is not done in real time, but queued to be executed as soon as possible with the available CPU capacity.

Computation capabilities are implemented through fan-less embedded computer VIA EPIA ME6000G. Its main characteristics are:

- CPU: $600 \mathrm{MHz}$ Fanless VIA Eden ${ }^{\mathrm{TM}}$ Processor, selected in order to be able to operate without additional cooling systems..

- VGA: Integrated VIA UniChrome ${ }^{\mathrm{TM}}$ AGP graphics with MPEG-2 decoding acceleration. Two display capacity to provide monitor for both Red Eye controller and pilot.

- $10 / 100$ Mbps Ethernet to have connectivity with the on board router subsystem.

- Two serial COM ports for IMU/GPS communication.

Internal communications between cameras and the computation module is implemented through an on-board RouterBOARD RB532A. Its main characteristics are:

- CPU: MIPS32 4Kc based $266 \mathrm{MHz}$ embedded processor.

- Memory: 64MB DDR onboard memory chip.

- $3 \times 10 / 100 \mathrm{Mbps}$ Ethernet.

- 2 x MiniPCI for Wifi and WiMax links.

The Red Eye system will continuously transmit to the ground the basic information on the position of the helicopter and the pictures that have been taken (only the position). If thermal signatures are detected, the application will identify those pictures and schedule them to be transferred to the ground if requested. All other pictures will be stored for post-mission analysis.

Screens and interfaces are also present in order to implement a control application and to provide visual cues to the helicopter pilot to guarantee that the flight path corresponds as much as possible to the one that better fits the area exploration underway. The main control screen is designed to offer access to the monitoring procedures, the monitoring flight-paths, the acquired images, the position of the ground teams, etc. This screen offer both touch screen interface and a joystick for precise pointer positioning.

A second small screen is placed at the pilot position providing him immediate guidance in terms of correct altitude, heading, lateral displacements, and initial and final points with respect the monitoring flight paths. This screen is just informative and its information will depend on the operational mode that has been selected by the controller.

\section{AIR AND/OR GROUND COMMAND SYSTEM}

The designed command and control systems software on board the helicopter and on the ground are almost identical. The main difference between them is the latency required to get the image information. On board the helicopter images can be reviewed as soon as acquired (although hot-spot detection will require certain computation time). On the ground, images can be seen under request and the latency of the transmission will be much longer and will depend on the distance from the helicopter to the ground control.

The operation of the command and control software is divided in five different phases, namely:

(1) System configuration. 

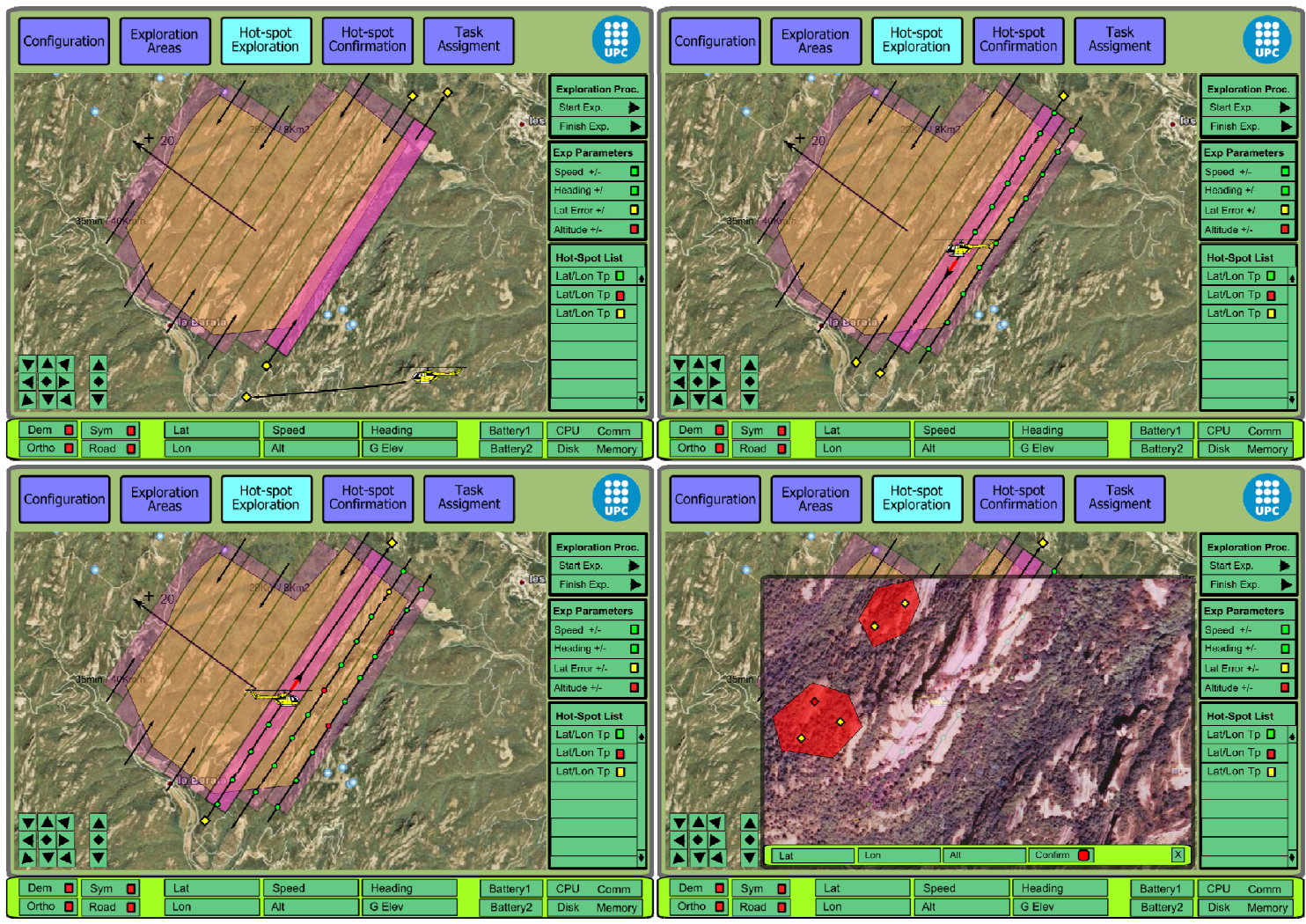

\section{Figure 7. Hot spot detection during the area scanning process. Images can be analyzed as soon as available in order to confirm/discard the detection.}

(2) Definition of exploration areas.

(3) Hot-spot exploration.

(4) Hot-spot confirmation.

(5) Ground squad task assignment.

\section{System configuration.}

The system configuration screen allows configuring the system in order to define the preferred exploration altitudes and speeds according to the desired resolution in each phase of the operation (exploration/confirmation) according to the available combination of camera/optics.

Information indicating the location of the ground control station, landing sites, identification of the available ground squads can be also specified.

Finally, restricted areas can also be specified to indicate population areas not to be directly over flown and/or especially dangerous obstacles like towers or electric lines.

\section{Definition of exploration areas.}

The areas to be explored need to be specified by the operator by means of a closed polygon. Each polygon implies, at least, a separated exploration by the helicopter.
The Red Eye system automatically offers an exploration solution defined by a number of trapezoidal areas to be scanned through linear tracks over flown by the helicopter at the specified distance to the ground. The particular altitude to be flown in each pass will depend on the variations of the terrain elevation (available through a Digital Elevation Model of the area).

Figure 6 shows different views of the application for two different exploration areas. The main direction of the terrain elevation is specified by an arrow annotated with the average terrain slope. High slopes will force perpendicular explorations to avoid flying into the ground, while small slopes can be ignored is the selected altitude guarantees than no collision is possible.

\section{Hot-spot exploration.}

Once the exploration scans have been properly defined, the scanning process itself can be started. The system automatically generates Initial Scan Points (ISP) and Final Scan Points (FSP) to guide the task of the pilot. The ISP allows the pilot to properly align the vehicle with the exploration track, while the FSP provides room for the turning maneuver and the re-alignment with the following exploration track. 

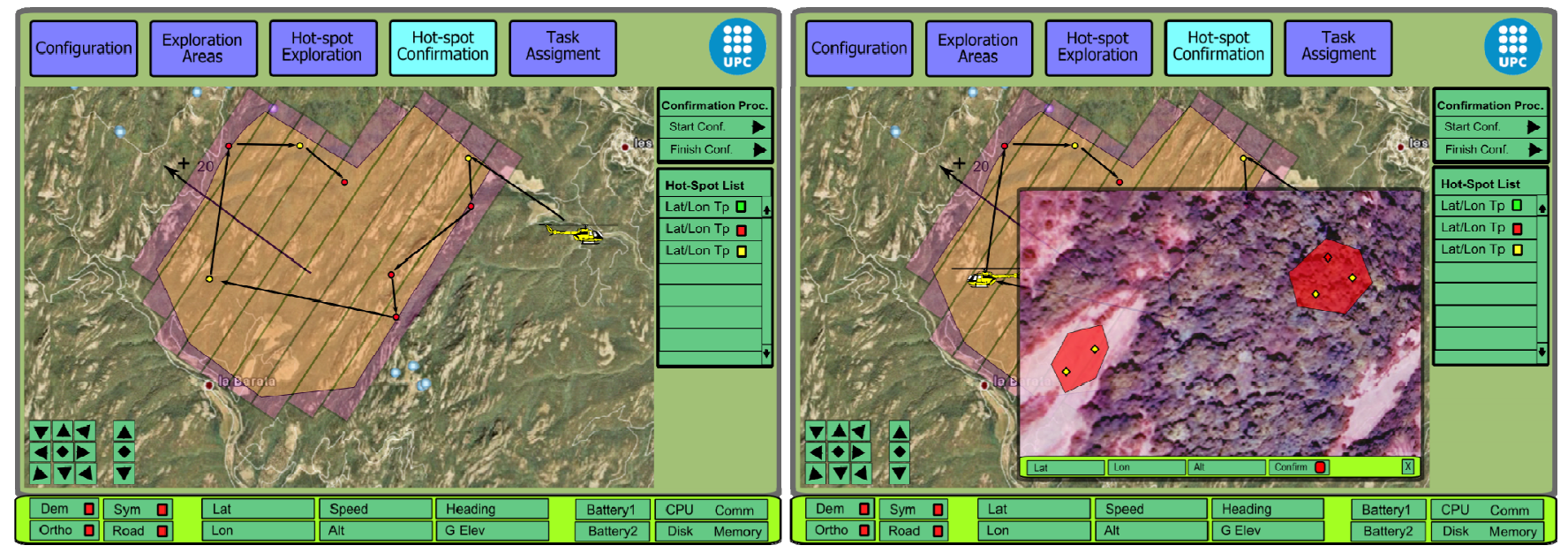

Figure 8. Hot spot confirmation process with real-time review of potential yet undecided hightemperature detections.

During the each exploration track the Red Eye cameras are automatically activated in order to gather images at the required frame rate (that will depend on the camera/optics, the selected altitude and the desired frame overlapping between consecutive frames). Each frame acquisition is indicated on the screen as a green dot. Frame acquisition stops once the FSP is surpassed and re-stars as soon as the helicopter gets into the next $I S P$.

While the exploration is being completed thermal images are being analyzed in order to determine if they have a significant thermal signature. In that case the corresponding dots may turn into red or yellow, depending on the intensity of the thermal signature. Additionally, the source of the hot spot is identified inside the image and then geo-referenced according to the information provided by the IMU and GPS at the time of the acquisition. The analyzed information is offered to the controller in order to confirm if it is a real hot-spot or maybe stray heat reflections from some element on the ground (rocks, human-made devices, etc.). Thermal images can be over imposed on top of high-definition images in order to facilitate the identification of the hotspot.

Explorations are selected at user's discretion and can be repeated if necessary and/or interleaved with the confirmation phase.

\section{Hot-spot confirmation.}

After an exploration is being completed some detected hotspots may be still undecided. The Red Eye system offers support to design a trajectory that overflies all undecided hot-spots in order to analyze them at a lower altitude and/or during a hovering flight. Having a closer look on the potential hot-spot should help deciding its relevance.

Hot-spots are processed sequentially following the sequence suggested by the application. Confirmation sequences can be repeated after the ground squads have refreshed the area.
In that way, detected hot-spots can be revisited to determine if the extinguishing task have been successful.

\section{Ground squad task assignment.}

Given the set of confirmed hot-spots, the controller can assign them to the available ground squads working on the area. Ground squads will receive all information available on the hot-spot like its position, thermal and visible images and any available detection information.

Once the squad has identified the hot spot and worked on it, they will communicate the controller through the application that the spot has been processed. During this process, the controller will be able to follow the progression of the teams on its screen.

\section{GROUND-BASED SYSTEMS}

Adhoc networks are packet-based multi-node networks that are gaining popularity in other cooperative environments because they do not need a central point of organization (like an access point in Wi-Fi networks) and they can be self-configured as nodes appear and disappear. If we add dynamism and mobility we reach the concept of MANET, Mobile Adhoc Network [10].

MANETs can extend a network more than the range of a single node range because their inherent multi-hoping capability allows the use of intermediate nodes to propagate packets to its destination.

The Red Eye system offers the ground squads a PDA system that can receive the set of hot-spots they have been tasked by the controller. The PDA set feeds back the position of the squad given its attached GPS. The PDA set can also be instrumented in order to feedback other information like temperature, humidity level and wind speed and direction. These data samples are designed to be 
sporadic because they need the proper placement of the sensors. However, the GPS position will be continuously transmitted.

The main advantage of using a MANET infrastructure is that information can get to the squads either directly from the Red Eye helicopter of relayed from some other ground squad, thus minimizing the "out of coverage" situations. Also, having a continuous monitoring of the ground squads will improve their efficiency as well as prevent dangerous situations in case of major changes in the evolution of the wildfire.

\section{Conclusions}

Having aerial resources working in a command and control over wildfires may improve the overall extinguishing process. Improving the awareness trough those monitoring systems may will maximize the efficiency of the available resources and at the same time improve the safety of the personnel working on the fire. However the complexity of integrating these monitoring systems together with the traditional aerial resources is a complex and unsolved task.

The Red Eye system is a partial solution to this task. Its objective is to provide hot-spot detection over areas in which other aerial resources has been temporally removed. It has been identified by GRAF, a specialized support group part of the firefighter in Catalonia (Spain), that this scenario may provide important benefits in terms of efficiency. Red Eye will allow aerial and ground resources to be employed on other fire fronts by reducing the number of resources that need to be kept on the field one a fire front has been controlled.

The Red Eye system has been designed and prototyped and will be tested during the prescribed fire campaign that is regularly being implemented by fire fighters in springtime.

\section{ACKNOWLEDGEMENTS}

This work has been partially funded by the Ministry of Science and Education of Spain under contract TIN 200763927 and by the Generalitat de Catalunya under the Pyrenees Collaborative Action.

\section{REFERENCES}

[1] Wegener, V. A. S. and Brass, J., "The UAV Western States Fire Mission: Concepts, Plans and Developmental Advancements", AIAA $3^{\text {rd }}$ Unmanned Unlimited Technical Conference, Workshop and Exhibit, AIAA, Chicago, Illinois, 2004.

[2] Loegering, G., "Global Hawk - A New Tool for Airborne Remote Sensing", 1st UAV Conference, AIAA, Portsmouth, Virginia, 2002.
[3] Nichols, J. D., "Firefly system concept", Proc. SPIE Vol. 1540, p. 202-206, Infrared Technology XVII, Bjorn F. Andresen; Marija S. Scholl; Irving J. Spiro; Eds., edited by B. F. Andresen, M. Scholl, and I. J. Spiro, Dec. 1991

[4] Kaufman, Y., Justice, C., Flynn, L., Kendall, J., Prins, E., Giglio, L., Ward, D., Menzel, W., and Setzer, A., "Potential global fire monitoring from EOS-MODIS", Journal of Geophysical Research, Vol. 103, No. 32, 1992, pp. 215-238.

[5] Giglio, L., Descloitres, J., Justice, C., and Kaufman, Y., "An enhanced contextual fire detection algorithm for MODIS", Photogrammetric Engineering and Remote Sensing, Vol. 87, 2003, pp. 273-282.

[6] Casbeer, D., Kingston, D., Beard, R., and McLain, T., "Cooperative forest fire surveillance using a team of small unmanned air vehicles", International Journal of Systems Science, Vol. 37, No. 6, 2006, pp. 351-360, Publisher: Taylor and Francis Ltd.

[7] Ononye, A., Vodacek, A., and Saber, E., "Automated extraction of fire line parameters from multispectral infrared images", Remote Sensing of Environment, Vol. 108, No. 2, 2007, pp. 179--188, also AIAA Paper 89-0269, Jan. 1989.

[8] Wright, D., Yotsumata, T., and El-Sheimy, N., "Real Time Identification and Location of Forest Fire Hotspots from Geo-referenced Thermal Images", International Archives of Photogrammetry Remote Sensing and Spatial Information Sciences, Vol. 35, No. 2, 2004, pp. 13-18, also AIAA Paper 89-0269, Jan. 1989.

[9] J. Lopez, P. Royo, E. Pastor, C. Barrado, and E. Santamaria, "A middleware architecture for unmanned aircraft avionics," ACM/IFIP/USEUNIX 8th Int. Middleware Conference, NewPort, California, Nov. 2007.

[10] S. Jadhav, T. X Brown, S. Doshi, D. Henkel, R.-G. Thekkekunnel, "Lessons Learned Constructing A Wireless Ad Hoc Network Test Bed," in Proc. of the Wireless Network Measurement Workshop, Trentino, Italy, 3 Apr. 2005. 


\section{BIOGRAPHY}

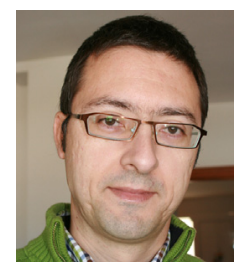

Enric Pastor is a Computer Science Engineer and holds Ph.D. also in Computer Science from the Technical University of Catalonia (Spain). Currently, he is an associate professor at the Castelldefels School of Technology. His research background includes the development of CAD tools for the automatic design of synchronous and asynchronous circuits, and CAV tools for the formal verification of concurrent systems. He has published more than 30 journals and conference papers in these fields. Dr. Pastor is leading the ICARUS (Intelligent Communications and Avionics for Robust Unmanned Aerial Systems) Research Group, completely focused on the development of systems that support and facilitate practical applications of UAS technology. The ICARUS group is especially interested in developing wildland fire monitoring tools and strategies both using UAS technology and classical vehicles. The ICARUS group has published more that 15 research papers on UAS technology in the last three years.

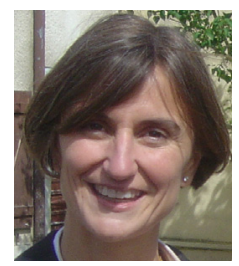

Cristina Barrado holds a Ph. D. on Computer Sciences by the Technical University of Catalonia, where she is also an Associate Professor at the Castelldefels School of Technology, Spain. She has been teaching operating systems since 1990 and currently a course of Digital Avionics Systems. Her Ph.D. Thesis was focused on automatic extraction of low level parallelism on loops at compile time. She belongs to the ICARUS Research Group, which target is the research on Unmanned Aerial Systems, their architecture, their civil uses and their integration into the airspace.

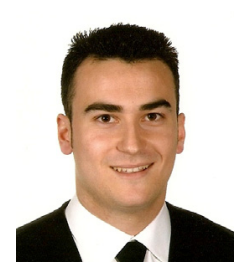

Pablo Royo received a degree in Telecommunication Engineering from the Technical University of Catalonia. Now, he is an assistant professor at the Technical University of Catalonia. His research interests include the Unmanned Aerial System design and their application in autonomous intelligent applications.

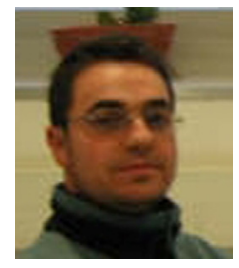

Juan Lopez is an assistant professor at the Technical University of Catalonia. Its main interests are embedded software architectures and unmanned aircraft systems design. Currently, he is working in middleware based avionics architectures for UAS.

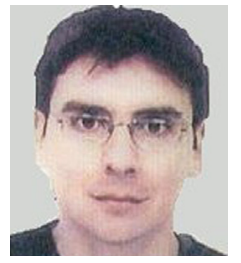

Eduard Santamaria received his master degree on Computer Science from the Technical University

of Catalonia (UPC) in 1998. After a short period working in the industry, in 2000 he joined UPC's Computer Architecture Department, first as a research assistant and later on as an assistant professor. He is pursuing his $P h D$ and his research is focused on mechanisms for mission specification and execution for Unmanned Aerial Vehicles.

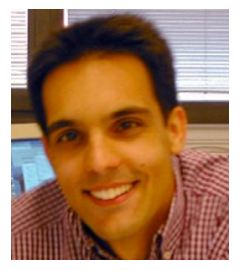

Xavier Prats is an Aeronautical Engineer of the National School for Civil Aviation (ENAC) located in Toulouse (France) and also holds a Telecommunications Engineer degree from the Technical University of Catalonia (UPC) located in Barcelona (Spain). He is currently pursuing a Ph.D. in Aerospace Engineering at the UPC in the field of aircraft trajectory optimization and works as Assistant Professor at UPC (EPSC Campus) since 2002. His research interests are air traffic management issues as well as the study of new Unmanned Air Vehicles (UAVS) technologies in order to use them in civil non-segregated airspace.

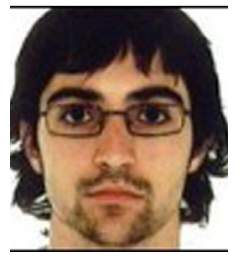

Josep M. Batlle received a degree in Telecommunication Engineering from the Technical University of Catalonia. Currently he is attending the Electronic Engineering degree and collaborates with the ICARUS research group on embedded system development. 